\title{
Exercise and Weight Loss: What Is the Evidence of Sex Differences?
}

\author{
Todd Alan Hagobian • Nero Evero
}

Published online: 6 November 2012

(C) Springer Science+Business Media New York 2012

\begin{abstract}
Regular physical activity, in the form of structured daily exercise, plays a large role in obesity management. Previous studies suggest that when sedentary men and women start an exercise training program, men lose more body weight than women. This has led researchers to reason that women are better at defending weight than men in response to exercise. In this article, we review exercise studies examining weight loss in men and women, and highlight hormonal, neuronal, and ad libitum energy intake responses to physical activity that is consistent with or in disagreement with sex differences in weight loss. The developing story may impact our view on the use of physical activity to influence body weight and whether a true sex difference is evident.
\end{abstract}

Keywords Exercise $\cdot$ Physical activity $\cdot$ Weight loss $\cdot$ Sex differences $\cdot$ Gender differences $\cdot$ Energy balance $\cdot$ Energy intake $\cdot$ Ad libitum · Appetite hormones · Ghrelin · Insulin . Leptin $\cdot$ Satiety $\cdot$ Neuronal response $\cdot$ Brain activity · Energy expenditure

\section{Introduction}

Excess body weight is one of the greatest public health crises facing the U.S. Approximately $68 \%$ of the adult U.S. population is overweight or obese, and the prevalence of obesity is now similar between men and women $(35.5 \%$ vs. $35.8 \%$, respectively) $[1,2]$. Overweight and obesity

\section{T. A. Hagobian $(\bowtie) \cdot$ N. Evero}

Kinesiology Department, California Polytechnic State University,

1 Grand Avenue,

San Luis Obispo, CA 93405, USA

e-mail: thagobia@calpoly.edu

N. Evero

e-mail: neevero@gmail.com greatly increases the risk for chronic disease including cardiovascular disease, diabetes, and some cancers [3, 4]. Thus, strategies to promote weight loss and/or prevent weight gain are of the utmost importance. Regular physical activity, in the form of structured daily exercise, plays a large role in body weight and obesity management. However, some exercise intervention studies suggest that men lose more weight than women. In this review, we will examine the exercise intervention studies and whether there is evidence of sex differences in weight loss. Moreover, we will highlight hormonal, appetite, and neuronal responses to physical activity that are consistent with or in disagreement with sex differences in weight loss.

\section{Exercise and Weight Loss}

In general, energy restriction, and not increasing energy expenditure via exercise alone, is the most common means to lose weight $[5,6]$. Regular physical activity typically results in modest [5-7], if any, weight loss but is a critical component of preventing weight regain $[8,9]$. In a recent review, Jakicic [5] concluded that exercise alone, relative to controls, results in $<3 \%$ body weight loss (approximately 0.5-3 kg). The recent American College of Sports Medicine position stand states, " $150-200 \mathrm{kcal} /$ week of moderate intensity exercise does not result in clinically significant weight loss" [10]. Thus, a larger dose of physical activity (>2000 kcal/week) or physical activity combined with energy restriction is necessary to produce greater weight loss [11-13].

Surprisingly, there is a lack of randomized controlled exercise studies comparing weight loss in men and women (see Table 1 for complete list of studies). To our knowledge, the Midwest Exercise Trial by Donnelly and colleagues is the only randomized controlled, supervised exercise trial to 
compare weight loss between sexes [14-16]. Overweight and obese men and women were randomized to an exercise (45 minutes day, 5 days per week) or a control group, and energy intake was allowed to vary (i.e., no intervention to restrict energy intake). After 16 months, men in the exercise group lost $\sim 5 \mathrm{~kg}$, whereas controls stayed the same weight. In contrast, women in the exercise group had a small weight gain (approximately $+0.6 \mathrm{~kg}$ ), while the control group had a much larger weight gain (approximately $3.0 \mathrm{~kg}$ ). This is supported by another study showing that 40 weeks of exercise training significantly lowered weight (approximately $1.0 \mathrm{~kg} ; \mathrm{P}<0.01)$ in men [17]. In contrast, exercise training did not significantly promote weight loss (approximately $0.9 \mathrm{~kg}, \mathrm{P}>0.05$ ) in women [17]. Despite men and women responding differently to exercise, the clinical meaningfulness of $\sim 1 \mathrm{~kg}$ of weight loss is questionable. Taken together, these data suggest that; 1) men lose more body weight than women in response to long-term exercise training, 2) women more accurately match energy intake with exercise expenditure and ultimately maintain body weight, and 3) men do not completely compensate by increasing energy intake to maintain energy balance and therefore are able to maintain an energy deficit and lose weight.

In spite of the findings mentioned above, emerging data suggests that men and women lose equivalent amounts of weight in response to exercise training. McTiernan et al. [18] randomly assigned men and women to an exercise group (facility or home-based at $60 \mathrm{~min} / \mathrm{d}, 6 \mathrm{~d} /$ week) or control group for 12 months. Relative to controls, exercising men and women lost a significant amount of weight $(-1.8 \mathrm{~kg},-1.4 \mathrm{~kg}$, respectively), with no difference between sexes. Recently, Caudwell et al. [19••] found that 12 weeks of supervised exercise $(5 \mathrm{~d} / \mathrm{wk}$; exercise expenditure $=500 \mathrm{kcal} / \mathrm{d})$ significantly reduced mean weight in men $(-3.0 \mathrm{~kg})$ and women $(-2.3 \mathrm{~kg})$, with no difference between sexes. It is important to note that this was not a randomized study and did not have a control group. However, a central component of this study was that the exercise was lab based and supervised, suggesting that this may be a key to explaining differences between men and women (i.e., when exercise is prescribed but not supervised, sex differences might occur). Moreover, these data challenge the idea that women, compared to men, are better at defending weight and lose less weight in response to exercise.

Why the discrepant results in weight loss after exercise in men and women? When interpreting these data it is important to consider methodological factors that were (not) controlled when comparing exercise-induced weight loss in men and women. Moreover, others and we have designed studies to address whether biological differences may potentially explain differences in exercise-induced weight loss in men and women.

\section{Exercise Energy Expenditure}

The most obvious explanation as to why men lose more weight than women in response to exercise is the difference in exercise energy expenditure. In the Midwest Exercise Trial $[14,15]$ mentioned above, exercise energy expenditure was noticeably higher in men compared to women ( $667 \mathrm{vs.}$ $439 \mathrm{kcal} /$ session, respectively). This resulted in a significant weight loss in men but not women. On the other hand, in the study by Caudwell et al. [19••], exercise energy expenditure was clamped for both sexes $(500 \mathrm{kcal} / \mathrm{session}$ or $2500 \mathrm{kcal} /$ wk), which resulted in similar amounts of weight loss in men and women. However, it may be more challenging for women to achieve the same target exercise expenditure as men given that they have a lower weight and lower total daily energy expenditure. To achieve the same target exercise expenditure as men, women may need to exercise for a longer duration and/or at a higher intensity. It is important to note, that individual weight loss with exercise appears to be highly variable in both sexes. For example, Caudwell et al. [19・•] showed that weight loss ranged from a loss of $14 \mathrm{~kg}$ to a gain of $4 \mathrm{~kg}$ in both sexes. In a series of exercise studies, Donnelly et al. [20] found in women almost half lost weight and half gained weight, whereas most men lose weight. Moreover, Bouchard [21] reported weight loss ranging from 3 to $12 \mathrm{~kg}$ after 4 months of exercise training in men. These data indicate in some individuals other components of the energy balance equation (i.e., energy intake, resting metabolic rate, non-exercise activity thermogenesis) are altered to preserve weight. Collectively, these data suggest that: 1) the amount of exercise expenditure plays a pivotal role in the observed sex differences in weight loss after exercise, 2) when basing exercise on the same duration and intensity in men and women as in the Midwest Exercise Trial, exercise expenditure is typically higher in men compared to women and may lead to differences in weight loss, 3) altering the duration of exercise to match energy expenditure between sexes may lead to similar weight loss in men and women, and 4) weight loss with exercise alone is highly variable regardless of sex.

\section{Exercise and Appetite Hormones}

To potentially explain sex differences in weight loss via exercise, previous studies have examined whether appetiteregulating hormones are different in men and women in response to exercise $[22 \cdot, 23]$. The premise behind assessing sex differences in appetite hormones is that women are better at defending weight and will increase energy intake to match the new higher energy expenditure, whereas men will not compensate by increasing energy intake and lose weight. This implies that differential effects of exercise on 
Table 1 Summary of exercise studies evaluating sex differences in weight loss

\begin{tabular}{|c|c|c|c|c|c|}
\hline Study & Subject population & $\begin{array}{l}\text { Randomized } \\
\text { controlled intervention }\end{array}$ & $\begin{array}{l}\text { Supervised exercise } \\
\text { and duration of study }\end{array}$ & Exercise prescription & Weight loss \\
\hline \multirow[t]{3}{*}{ Caudwell et al. [19••] } & Overweight/obese & No & Yes; 12 weeks & $5 \mathrm{~d} / \mathrm{wk}$ & \\
\hline & Men: $\mathrm{N}=35$ & & & $43 \mathrm{~min} / \mathrm{d}$, expenditure: $2500 \mathrm{kcal} / \mathrm{wk}$ & $-3 \mathrm{~kg}$ \\
\hline & Women: $\mathrm{N}=72$ & & & $54 \mathrm{~min} / \mathrm{d}$, expenditure: $2500 \mathrm{kcal} / \mathrm{wk}$ & $-2.3 \mathrm{~kg}$ \\
\hline \multirow[t]{3}{*}{ Donnelly et al. [15] } & Overweight/Obese & Yes & Yes; 16 months & $5 \mathrm{~d} / \mathrm{wk}$ & \\
\hline & Men: $N=31$ & & & $45 \mathrm{~min} / \mathrm{d}$, expenditure: $677 \mathrm{kcal} / \mathrm{d}$ & $-5.2 \mathrm{~kg}$ \\
\hline & Women: $\mathrm{N}=43$ & & & $45 \mathrm{~min} / \mathrm{d}$, expenditure: $439 \mathrm{kcal} / \mathrm{d}$ & $+0.6 \mathrm{~kg}$ \\
\hline \multirow[t]{3}{*}{ Despres et al. [7] } & No BMI reported & No & Yes; 20 weeks & $5 \mathrm{~d} / \mathrm{wk}$ & \\
\hline & Men: $N=7$ & & & $45 \mathrm{~min} / \mathrm{d}$, expenditure not reported & $-1.2 \mathrm{~kg}$ \\
\hline & Women: $\mathrm{N}=12$ & & & $45 \mathrm{~min} / \mathrm{d}$, expenditure not reported & $+0.8 \mathrm{~kg}$ \\
\hline \multirow[t]{3}{*}{ McTiernan et al. [18] } & Overweight/Obese & Yes & No; 12 months & $6 \mathrm{~d} / \mathrm{wk}$ & \\
\hline & Men: $N=100$ & & & $60 \mathrm{~min} / \mathrm{d}$, expenditure not reported & $-1.8 \mathrm{~kg}$ \\
\hline & Women: $\mathrm{N}=102$ & & & $60 \mathrm{~min} / \mathrm{d}$, expenditure not reported & $-1.4 \mathrm{~kg}$ \\
\hline \multirow[t]{3}{*}{ Westerterp et al. [17] } & Normal-weight/Overweight & No & Yes; 44 weeks & $4 \mathrm{~d} / \mathrm{wk}$ & \\
\hline & Men: $N=16$ & & & $30-90 \mathrm{~min} / \mathrm{d}$, expenditure not reported & $-1.0 \mathrm{~kg}$ \\
\hline & Women: $\mathrm{N}=16$ & & & 30-90 $\mathrm{min} / \mathrm{d}$, expenditure not reported & $-0.9 \mathrm{~kg}$ \\
\hline
\end{tabular}

weight loss and energy intake result, at least partially, from key appetite hormones that mediate energy balance.

Appetite hormones are generally categorized as episodic (short-term) and tonic (long-term) signals. Episodic signals help control meal initiation, meal size, and meal termination [24-26]. Acylated (active) ghrelin is widely regarded as the main episodic hormone that stimulates energy intake. Both animal and human data suggest that peripheral infusion of ghrelin increases energy intake [27, 28]. Moreover, Cummings et al. [24] found that ghrelin concentrations spike prior to a meal, which suggests a role in meal initiation. Others have found that an energy deficit, and ultimately weight loss, increases ghrelin concentrations [29-31]. Recent data also suggests that Peptide tyrosinetyrosine (PYY) plays a role in meal termination. Peripheral infusion of $\mathrm{PYY}_{3-36}$ (active form of PYY) decreases energy intake in animals and humans [32-34].

Tonic hormones, which include leptin and insulin concentrations, regulate overall energy balance and body weight (fat) over days or weeks. Animal data has consistently shown that higher concentrations of leptin and insulin decreases energy intake $[35,36]$. In humans however, the role of leptin and insulin to decrease energy intake is less clear. Obese individuals typically have higher concentrations of leptin and insulin, implying that they may be "resistant" to the effects of these hormones. Recent data suggest that low concentrations of these hormones stimulates energy intake [37-39]. Thus in humans, these hormones may be more sensitive and defend an energy deficit or lower weight to stimulate energy intake, as opposed to decreasing energy intake as initially thought.

In one of the first human studies designed to assess exercise-induced sex differences in appetite hormones,
Hickey et al. [23] exercised men and women for 12 weeks (4 days/wk, 45 minutes/day). Exercise significantly lowered (approximately -18\%) leptin and insulin concentrations in women. In contrast, exercise had no impact on these hormones in men. These data provide initial support that exercise alters appetite hormones in a direction expected to stimulate energy intake in women but not in men, and that women may be better at defending weight after exercise.

To comprehensively address the "exercise-induced sex differences in appetite hormones" question, we assessed [22•] appetite hormones in three conditions in previously sedentary, overweight/obese men and women; 1) noexercise baseline, 2) exercise in energy deficit (energy intake not raised to meet new higher exercise expenditure), and 3 ) exercise in energy balance (energy intake raised to meet exercise expenditure). We noted clear sex differences in appetite hormones in response to exercise. In women, acylated ghrelin was significantly higher and insulin concentrations significantly lower after exercise in energy balance, suggesting an independent effect of exercise alone. Exercise in energy deficit resulted in a more robust acylated ghrelin and insulin response in women. In contrast to women, in men we observed only lower insulin concentrations after exercise in energy deficit and no change in acylated ghrelin after exercise, regardless of energy status. It is important to note that energy intake was rigidly controlled (independent variable) in this study, which limits our ability to infer whether higher acylated ghrelin and lower insulin concentrations after exercise in women would increase actual energy intake. Others have found that exercise-induced weight loss increases ghrelin concentrations in women [29, $30,40]$, whereas men have no change in ghrelin concentrations after exercise-induced weight loss [41]. Taken 
together, these studies suggest that appetite hormones in women are altered in a direction expected to stimulate energy intake with exercise alone that is potentiated with an energy deficit. In contrast, men exhibit subtle, if any, changes in appetite hormones in response to exercise regardless of energy status. Clearly, more work needs to be done to determine whether long-term exercise (months/ years) impacts appetite hormones differently in men and women, and whether sex differences in appetite hormones have a meaningful influence on energy intake and weight loss in response to exercise.

\section{Exercise and Neuronal Responses}

Despite the clear sex difference in appetite hormones in response to exercise, little is known of how exercise impacts the neuroanatomical correlates that control energy intake. Moreover, even less is known how sex-based differences associated with acute and regular exercise, influences neurocognitive functioning and reward processing in the brain. In this section we will briefly discuss the emergence and utilization of neuroimaging techniques and review emerging evidence investigating exercise-related sex differences in neuronal response to food cues.

The regulation of energy intake is a complex, multifaceted process involving internal and external homeostatic and non-homeostatic signals. The homeostatic regulation of energy intake has gained considerable attention (see above) and involves key appetite hormones (e.g., acylated ghrelin, leptin) and their impact on energy intake [42, 43]. However, non-homeostatic signals, such as learned behaviors, cognitive state, social context, external cues, and availability of food, also play a large role in the regulation of energy intake [44-46]. Ultimately, the interaction of homeostatic and nonhomeostatic signals determines whether to initiate and terminate a meal, and how much food to consume. However, the process of how the brain incorporates these signals remains unclear.

With advancements in spatial and temporal resolution in neuroimaging, specifically functional magnetic resonance imaging (fMRI), it is possible to monitor dynamic processes ongoing in the brain using BOLD signals as a measure of neural activity [47] to gain a understanding of the regulation of energy intake. Several studies have evaluated neuronal responses to visual food cues at rest, showing changes in brain regions essential to the regulation of energy intake [48-56]. Killgore et al. [51] observed significant activity in numerous food reward, inhibitory control, and visual brain regions (e.g., insula, amygdala, medial frontal gyrus, precuneus, etc.) in response to visual food cues. A recent meta-analysis showed the most concurrent brain regions activated in response to visual food cues were the fusiform gyrus, orbitofrontal cortex and insula [57], all of which play a central role in controlling energy intake. Moreover, studies have shown that brain activity varies by sex. Kilgore and Yurgelun-Todd [54] found that women relative to men, showed greater neuronal responses in the prefrontal cortex (food reward region), specifically the inferior frontal gyrus. In addition, Uher et al. [58] found that women, compared to men, had a stronger response in the insula (food reward brain region). Others have found that women have greater neuronal responses in food reward regions (i.e., putamen) and other taste brain regions [59]. Collectively, these data suggest that at rest women, compared to men, have greater neuronal responses in superficial food reward brain regions. In contrast, men tend to have greater neuronal responses in deeper brain region (e.g., hypothalamus) that controls energy intake.

Surprisingly little is known about how exercise affects food reward centers in the brain. To directly address this question, we had 30 (17 men and 13 women), healthy, normal-weight, subjects complete 60-minute of highintensity exercise or 60-minutes of rest (no-exercise), in a counterbalanced, crossover fashion [60•]. Immediately after each condition, BOLD signals in response to high-energy foods (e.g., chocolate cake, etc.), low-energy foods (e.g., vegetables, etc.) and control images (e.g., brick walls, etc.) were measured. We found that aerobic exercise, compared to the rest condition, reduced the neuronal response in food reward (i.e., insula, orbitofrontal cortex, putamen, rolandic operculum) and visual attention (i.e., inferior and middle occipital gyrus) brain regions. This is consistent with a recent study [61] showing that chronic exercise (4060 minutes/day for 6 months) lowered the neuronal response in the insula (food reward region) in overweight/obese individuals. Thus, these data suggest that both acute and chronic aerobic exercise reduces neuronal responses in food reward and visual attention brain regions, consistent with reducing the pleasure and palatability of food, incentive motivation to eat, and anticipation and consumption of food

In exploratory analyses (unpublished observation), we recently assessed exercise-induced changes in neuronal responses in men and women analyzed separately. We found that men had reduced neuronal responses in visual-attention brain regions (e.g., right inferior occipital gyrus, etc.). Women displayed reduced neuronal responses in both visual-attention (e.g., left middle occipital gyrus, etc.) and motor control brain regions (e.g., left supplemental motor area, etc.). Interestingly though, in men the extent of deactivation in visual attention regions was greater, suggesting that they are less responsive to food cues. This is in line with others showing sex differences in visual-attention brain regions $[50,62]$. The greater activity in the visual cortices may be an important component in the cognitive process of the control of energy intake and of related behavior in 
women. However, it is important to note that no published data has directly assessed whether exercise alters brain activity differently in men and women (we conducted analyses separately in men and women), and whether this plays an important role in potential sex differences in weight loss with exercise training.

\section{Exercise and Ad Libitum Energy Intake}

Emerging data has shown that exercise has a strong impact on ad libitum energy intake [63-68]. For example, King et al. showed that 60 minutes of swimming suppressed relative energy intake (energy intake minus energy cost of exercise), compared to a resting condition, in trained men [65]. In women, acute exercise may also lower relative energy intake [66], but weight status seems to play a pivotal role as obese, compared to normal-weight, appear to consume more food after exercise [69]. Surprisingly, none of these studies were designed to assess sex differences. Thus, we recently determined whether men and women, when exposed to the same relative exercise treatment, have different ad libitum energy intake and whether this may be explained by differences in appetite hormones [70॰. Men and women either rested or exercised on a cycle ergometer at $70 \%$ of $\mathrm{VO}_{2}$ peak until $30 \%$ of total daily energy expenditure was expended, in a crossover, counterbalanced fashion. To potentially control for confounding variables, we matched men and women on body mass index and cardiorespiratory fitness levels, and all women were studied in the early follicular phase of the menstrual cycle.

Surprisingly, we found a clear effect of exercise on energy intake regardless of sex. Specifically, relative energy intake was significantly suppressed after exercise, compared to rest, in both men $(672 \pm 827,1133 \pm 619 \mathrm{kcal}$, respectively) and women $(-121 \pm 243,530 \pm 233 \mathrm{kcal}$, respectively). Additionally, there was no compensatory increase in total energy intake after exercise (i.e., similar total energy intake in exercise and rest conditions) in both sexes. Moreover, we found that the majority of men and women ( 19 of 21 subjects) were able to maintain an energy deficit after the exercise condition such that energy intake was not sufficiently increased to match or exceed exercise expenditure. However, we observed a huge variability as $\sim 30 \%$ of subjects lowered energy intake after exercise compared to rest condition, whereas the other subjects had higher energy intake after exercise compared to rest condition. The large variability in energy intake is in line with previous exercise studies reporting individual energy intake data $[66,68]$. Thus, results of this study showed that acute exercise suppresses relative energy intake regardless of sex, which is consistent with the medium to long-term exercise studies [18, 19••] showing men and women lose similar amounts of weight.

It is important to note that we assessed energy intake at a single ad libitum buffet meal, which limits our ability to infer whether these changes would manifest over-time. When extending daily exercise to weeks or months, sex differences in energy intake have been noted in some but not all studies. In a series of studies, Stubbs and colleagues $[71,72]$ showed that there was no compensation in energy intake with 7 days of exercise in men. In contrast, women partially compensate by increasing energy intake $(+33 \%)$ in response to the same 7 days of exercise. Moreover, Martins et al. [73] assessed whether 6-weeks of exercise training impacts cumulative 24-hour energy intake in men and women. After the exercise intervention, a high-energy preload meal, compared to a low-energy preload, significantly lowered 24-hour energy intake in men. In women however, 24-hour energy intake was unaffected after exercise training. In contrast, Caudwell et al. [19••] found no sex difference in 24-hour energy intake or the satiety response after 12-weeks of exercise training. Taken together, at this time the data is mixed as to whether women, but not men, increase energy intake in response to exercise. More research is obviously needed to disentangle the complex relationship between exercise, ad libitum energy intake, and sex differences.

\section{Conclusions}

It has generally been implied that men lose more weight than women in response to regular exercise. This had led researchers to reason that women are better at defending weight, and increase energy intake to match the higher exercise expenditure. In support, others and we have found that women have more robust changes in appetite hormones in a direction expected to stimulate energy intake. The data assessing sex differences in ad libitum energy intake and brain activity are mixed and/or inconclusive however. Moreover, recent data has challenged the paradigm that sex differences exist in weight loss in response to exercise when men and women are clamped at the same exercise expenditure [19••]. Dissemination of these data is critical to show that modest weight loss is achievable with exercise (even in women), and in terms of potentially influencing exercise recommendations for the lay public. In the coming years, the Midwest Exercise Trial II [74], which is designed to assess men and women on the same relative and absolute amount of exercise expenditure, will shed more light on weight loss with exercise. Thus, the evolving story as to whether there is a true sex difference in exercise-induced weight loss will continue to progress as more research is amassed.

Conflicts of Interest T.A. Hagobian: has received grant support from Cal Poly Extramural Funding Initiative Grant; and was reimbursed by Cal Poly for travel to conference; N. Evero: none. 


\section{References}

Papers of particular interest, published recently, have been highlighted as:

- Of importance

•- Of major importance

1. Ogden CL, Carroll MD, Kit BK, Flegal KM. Prevalence of obesity and trends in body mass index among US children and adolescents, 1999-2010. JAMA. 2012;307(5):483-90.

2. Flegal KM, Carroll MD, Kit BK, Ogden CL. Prevalence of obesity and trends in the distribution of body mass index among US adults, 1999-2010. JAMA. 2012;307(5):491-7.

3. Must A, Spadano J, Coakley EH, Field AE, Colditz G, Dietz WH. The disease burden associated with overweight and obesity. JAMA. 1999;282(16):1523-9.

4. Mokdad AH, Ford ES, Bowman BA, et al. Prevalence of obesity, diabetes, and obesity-related health risk factors, 2001. JAMA. 2003;289(1):76-9.

5. Jakicic JM. The effect of physical activity on body weight. Obesity (Silver Spring). 2009;17 Suppl 3:S34-38.

6. Wing RR. Physical activity in the treatment of the adulthood overweight and obesity: current evidence and research issues. Med Sci Sports Exerc. 1999;31(11 Suppl):S547-552.

7. Despres JP, Bouchard C, Savard R, Tremblay A, Marcotte M, Theriault G. Effects of exercise-training and detraining on fat cell lipolysis in men and women. Eur J Appl Physiol Occup Physiol. 1984;53(1):25-30.

8. Brooks GA, Butte NF, Rand WM, Flatt JP, Caballero B. Chronicle of the Institute of Medicine physical activity recommendation: how a physical activity recommendation came to be among dietary recommendations. Am J Clin Nutr. 2004;79(5):921S-30S.

9. Catenacci VA, Ogden LG, Stuht J, et al. Physical activity patterns in the National Weight Control Registry. Obesity (Silver Spring). 2008;16(1):153-61.

10. Donnelly JE, Blair SN, Jakicic JM, Manore MM, Rankin JW, Smith BK. American College of Sports Medicine Position Stand. Appropriate physical activity intervention strategies for weight loss and prevention of weight regain for adults. Med Sci Sports Exerc. 2009;41(2):459-71.

11. Jakicic JM. Exercise in the treatment of obesity. Endocrinol Metab Clin N Am. 2003;32(4):967-80.

12. Jeffery RW, Wing RR, Sherwood NE, Tate DF. Physical activity and weight loss: does prescribing higher physical activity goals improve outcome? Am J Clin Nutr. 2003;78(4):684-9.

13. Jakicic JM, Marcus BH, Gallagher KI, Napolitano M, Lang W. Effect of exercise duration and intensity on weight loss in overweight, sedentary women: a randomized trial. JAMA: J Am Med Assoc. 2003;290(10):1323-30.

14. Donnelly JE, Hill JO, Jacobsen DJ, et al. Effects of a 16-month randomized controlled exercise trial on body weight and composition in young, overweight men and women: the Midwest Exercise Trial. Arch Intern Med. 2003;163(11):1343-50.

15. Donnelly JE, Kirk EP, Jacobsen DJ, Hill JO, Sullivan DK, Johnson SL. Effects of 16 mo of verified, supervised aerobic exercise on macronutrient intake in overweight men and women: the Midwest Exercise Trial. Am J Clin Nutr. 2003;78(5):950-6.

16. Potteiger JA, Jacobsen DJ, Donnelly JE, Hill JO. Glucose and insulin responses following 16 months of exercise training in overweight adults: the Midwest Exercise Trial. Metabolism. 2003;52(9):1175-81.

17. Westerterp KR, Meijer GA, Janssen EM, Saris WH, Ten Hoor F. Long-term effect of physical activity on energy balance and body composition. Br J Nutr. 1992;68(1):21-30.
18. McTiernan A, Sorensen B, Irwin ML, et al. Exercise effect on weight and body fat in men and women. Obesity (Silver Spring). 2007;15(6):1496-512.

19. • Caudwell P, Gibbons C, Hopkins M, King N, Finlayson G, Blundell J. No Sex Difference in Body Fat in Response to Supervised and Measured Exercise. Med Sci Sports Exerc 2012;Aug 14. This paper showed that the same target exercise expenditure results in similar weight loss in men and women.

20. Donnelly JE, Smith BK. Is exercise effective for weight loss with ad libitum diet? Energy balance, compensation, and gender differences. Exerc Sport Sci Rev. 2005;33(4):169-74.

21. Bouchard C, Tremblay A, Nadeau A, et al. Long-term exercise training with constant energy intake. 1: effect on body composition and selected metabolic variables. Int J Obes. 1990;14(1):57-73.

22. • Hagobian TA, Sharoff CG, Stephens BR, et al. Effects of exercise on energy-regulating hormones and appetite in men and women. Am J Physiol Regul Integr Comp Physiol. 2009;296(2):R233-242. This paper showed that women, compared to men, have a more robust appetite hormonal response in response to exercise.

23. Hickey MS, Houmard JA, Considine RV, et al. Gender-dependent effects of exercise training on serum leptin levels in humans. Am J Physiol. 1997;272(4 Pt 1):E562-566.

24. Cummings DE, Purnell JQ, Frayo RS, Schmidova K, Wisse BE, Weigle DS. A preprandial rise in plasma ghrelin levels suggests a role in meal initiation in humans. Diabetes. 2001;50(8):1714-9.

25. Cummings DE, Frayo RS, Marmonier C, Aubert R, Chapelot D. Plasma ghrelin levels and hunger scores in humans initiating meals voluntarily without time- and food-related cues. Am J Physiol Endocrinol Metab. 2004;287(2):E297-304.

26. Cummings DE. Ghrelin and the short- and long-term regulation of appetite and body weight. Physiol Behav. 2006;89(1):71-84.

27. Wren AM, Seal LJ, Cohen MA, et al. Ghrelin enhances appetite and increases food intake in humans. J Clin Endocrinol Metab. 2001;86(12):5992.

28. Wren AM, Small CJ, Ward HL, et al. The novel hypothalamic peptide ghrelin stimulates food intake and growth hormone secretion. Endocrinology. 2000;141(11):4325-8.

29. Leidy HJ, Dougherty KA, Frye BR, Duke KM, Williams NI. Twenty-four-hour ghrelin is elevated after calorie restriction and exercise training in non-obese women. Obesity (Silver Spring). 2007;15(2):446-55.

30. Leidy HJ, Gardner JK, Frye BR, et al. Circulating ghrelin is sensitive to changes in body weight during a diet and exercise program in normal-weight young women. J Clin Endocrinol Metab. 2004;89(6):2659-64.

31. Cummings DE, Weigle DS, Frayo RS, et al. Plasma ghrelin levels after diet-induced weight loss or gastric bypass surgery. N Engl J Med. 2002;346(21):1623-30.

32. Batterham RL, Cohen MA, Ellis SM, et al. Inhibition of food intake in obese subjects by peptide YY3-36. N Engl J Med. 2003;349(10):941-8.

33. Batterham RL, Le Roux CW, Cohen MA, et al. Pancreatic polypeptide reduces appetite and food intake in humans. J Clin Endocrinol Metab. 2003;88(8):3989-92.

34. Batterham RL, Cowley MA, Small CJ, et al. Gut hormone PYY(336) physiologically inhibits food intake. Nature. 2002;418 (6898):650-4.

35. Schulz C, Paulus K, Lehnert H. Central nervous and metabolic effects of intranasally applied leptin. Endocrinology. 2004;145 (6):2696-701.

36. Bruijnzeel AW, Corrie LW, Rogers JA, Yamada H. Effects of insulin and leptin in the ventral tegmental area and arcuate hypothalamic nucleus on food intake and brain reward function in female rats. Behavioural brain research. 2011;219(2):254-64.

37. Chan JL, Heist K, DePaoli AM, Veldhuis JD, Mantzoros CS. The role of falling leptin levels in the neuroendocrine and metabolic 
adaptation to short-term starvation in healthy men. J Clin Invest. 2003;111(9):1409-21.

38. Clegg DJ, Brown LM, Zigman JM, et al. Estradiol-dependent decrease in the orexigenic potency of ghrelin in female rats. Diabetes. 2007;56(4):1051-8.

39. Woods SC, Gotoh K, Clegg DJ. Gender differences in the control of energy homeostasis. Exp Biol Med (Maywood). 2003;228 (10):1175-80.

40. Foster-Schubert KE, McTiernan A, Frayo RS, et al. Human plasma ghrelin levels increase during a one-year exercise program. J Clin Endocrinol Metab. 2005;90(2):820-5.

41. Ravussin E, Tschop M, Morales S, Bouchard C, Heiman ML. Plasma ghrelin concentration and energy balance: overfeeding and negative energy balance studies in twins. J Clin Endocrinol Metab. 2001;86(9):4547-51.

42. Baskin DG, Figlewicz Lattemann D, Seeley RJ, Woods SC, Porte Jr D, Schwartz MW. Insulin and leptin: dual adiposity signals to the brain for the regulation of food intake and body weight. Brain Res. 1999;848(1-2):114-23.

43. Schwartz MW. Central nervous system regulation of food intake. Obesity (Silver Spring). 2006;14 Suppl 1:1S-8S.

44. Berthoud HR. Neural control of appetite: cross-talk between homeostatic and non-homeostatic systems. Appetite. 2004;43 (3):315-7.

45. Berthoud HR. Mind versus metabolism in the control of food intake and energy balance. Physiol Behav. 2004;81(5):781-93.

46. Zheng H, Lenard NR, Shin AC, Berthoud HR. Appetite control and energy balance regulation in the modern world: reward-driven brain overrides repletion signals. Int J Obes (Lond). 2009;33 Suppl 2:S8-13.

47. Tataranni PA, DelParigi A. Functional neuroimaging: a new generation of human brain studies in obesity research. Obes Rev. 2003;4(4):229-38.

48. Cornier MA. The effects of overfeeding and propensity to weight gain on the neuronal responses to visual food cues. Physiol Behav. 2009;97(5):525-30.

49. Cornier MA, Salzberg AK, Endly DC, Bessesen DH, Rojas DC, Tregellas JR. The effects of overfeeding on the neuronal response to visual food cues in thin and reduced-obese individuals. PLoS One. 2009;4(7):e6310.

50. Cornier MA, Salzberg AK, Endly DC, Bessesen DH, Tregellas JR. Sex-based differences in the behavioral and neuronal responses to food. Physiol Behav. 2010;99(4):538-43.

51. Killgore WD, Young AD, Femia LA, Bogorodzki P, Rogowska J, Yurgelun-Todd DA. Cortical and limbic activation during viewing of high- versus low-calorie foods. NeuroImage. 2003;19(4):1381-94.

52. Killgore WD, Yurgelun-Todd DA. Body mass predicts orbitofrontal activity during visual presentations of high-calorie foods. Neuroreport. 2005;16(8):859-63.

53. Killgore WD, Yurgelun-Todd DA. Affect modulates appetiterelated brain activity to images of food. Int $\mathrm{J}$ Eat Disord. 2006;39(5):357-63.

54. Killgore WD, Yurgelun-Todd DA. Sex differences in cerebral responses to images of high versus low-calorie food. Neuroreport. 2010;21(5):354-8.

55. Stice E, Spoor S, Bohon C, Veldhuizen MG, Small DM. Relation of reward from food intake and anticipated food intake to obesity: a functional magnetic resonance imaging study. J Abnorm Psychol. 2008;117(4):924-35.

56. Stoeckel LE, Weller RE, Cook 3rd EW, Twieg DB, Knowlton RC, Cox JE. Widespread reward-system activation in obese women in response to pictures of high-calorie foods. NeuroImage. 2008;41 (2):636-47.
57. van der Laan LN, de Ridder DT, Viergever MA, Smeets PA. The first taste is always with the eyes: a meta-analysis on the neural correlates of processing visual food cues. NeuroImage. 2011;55 (1):296-303.

58. Uher R, Treasure J, Heining M, Brammer MJ, Campbell IC. Cerebral processing of food-related stimuli: effects of fasting and gender. Behav Brain Res. 2006;169(1):111-9.

59. Smeets PA, de Graaf C, Stafleu A, van Osch MJ, Nievelstein RA, van der Grond J. Effect of satiety on brain activation during chocolate tasting in men and women. Am J Clin Nutr. 2006;83 (6):1297-305.

60. - Evero N, Hackett LC, Clark RD, Phelan S, Hagobian TA. Aerobic exercise reduces neuronal responses in food reward brain regions. J Appl Physiol. 2012;112(9):1612-9. This paper showed reduced activity in food reward brain regions after exercise.

61. Cornier MA, Melanson EL, Salzberg AK, Bechtell JL, Tregellas JR. The effects of exercise on the neuronal response to food cues. Physiol Behav. 2012;105(4):1028-34.

62. Del Parigi A, Chen K, Gautier JF, et al. Sex differences in the human brain's response to hunger and satiation. Am J Clin Nutr. 2002;75(6):1017-22.

63. Ueda SY, Yoshikawa T, Katsura Y, Usui T, Fujimoto S. Comparable effects of moderate intensity exercise on changes in anorectic gut hormone levels and energy intake to high intensity exercise. J Endocrinol. 2009;203(3):357-64.

64. King JA, Miyashita M, Wasse LK, Stensel DJ. Influence of prolonged treadmill running on appetite, energy intake and circulating concentrations of acylated ghrelin. Appetite. 2010;54(3):492-8.

65. King JA, Wasse LK, Stensel DJ. The acute effects of swimming on appetite, food intake, and plasma acylated ghrelin. J Obes 2011;2011.

66. Unick JL, Otto AD, Goodpaster BH, Helsel DL, Pellegrini CA, Jakicic JM. Acute effect of walking on energy intake in overweight/obese women. Appetite 2010.

67. Imbeault P, Saint-Pierre S, Almeras N, Tremblay A. Acute effects of exercise on energy intake and feeding behaviour. Br J Nutr. 1997;77(4):511-21.

68. Finlayson G, Bryant E, Blundell JE, King NA. Acute compensatory eating following exercise is associated with implicit hedonic wanting for food. Physiol Behav. 2009;97(1):62-7.

69. George VA, Morganstein A. Effect of moderate intensity exercise on acute energy intake in normal and overweight females. Appetite. 2003;40(1):43-6.

70. • Hagobian TA, Yamashiro M, Hinkel-Lipsker J, Streder K, Evero E, Hackney T. Effects of acute exercise on appetite hormones and ad libitum energy intake in men and women. Appl Physiol Nutr Metab 2012, In press. This paper showed that acute exercise suppressed relative energy intake in both men and women.

71. Stubbs RJ, Sepp A, Hughes DA, et al. The effect of graded levels of exercise on energy intake and balance in free-living men, consuming their normal diet. Eur J Clin Nutr. 2002;56(2):129-40.

72. Stubbs RJ, Sepp A, Hughes DA, et al. The effect of graded levels of exercise on energy intake and balance in free-living women. Int J Obes Relat Metab Disord. 2002;26(6):866-9.

73. Martins C, Truby H, Morgan LM. Short-term appetite control in response to a 6 -week exercise programme in sedentary volunteers. Br J Nutr. 2007;98(4):834-42.

74. Donnelly JE, Washburn RA, Smith BK, et al. A randomized, controlled, supervised, exercise trial in young overweight men and women: the Midwest Exercise Trial II (MET2). Contemp Clin Trials. 2012;33(4):804-10. 